2009s-04

\title{
Emulation in Teams and Families
}

\author{
Daniel Leonard, Ngo Van Long
}

\begin{tabular}{c}
\hline Série Scientifique \\
Scientific Series
\end{tabular}

\author{
Montréal \\ Mars 2009
}

(c) 2009 Daniel Leonard, Ngo Van Long. Tous droits réservés. All rights reserved. Reproduction partielle permise avec citation du document source, incluant la notice (C).

Short sections may be quoted without explicit permission, if full credit, including $\left({ }^{\circ}\right.$ notice, is given to the source.

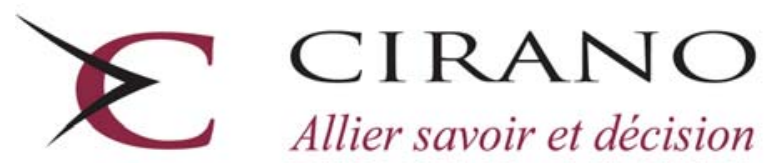

Centre interuniversitaire de recherche en analyse des organisations 


\section{CIRANO}

Le CIRANO est un organisme sans but lucratif constitué en vertu de la Loi des compagnies du Québec. Le financement de son infrastructure et de ses activités de recherche provient des cotisations de ses organisations-membres, d'une subvention d’infrastructure du Ministère du Développement économique et régional et de la Recherche, de même que des subventions et mandats obtenus par ses équipes de recherche.

CIRANO is a private non-profit organization incorporated under the Québec Companies Act. Its infrastructure and research activities are funded through fees paid by member organizations, an infrastructure grant from the Ministère du Développement économique et régional et de la Recherche, and grants and research mandates obtained by its research teams.

\section{Les partenaires du CIRANO}

\section{Partenaire majeur}

Ministère du Développement économique, de l’Innovation et de l’Exportation

\section{Partenaires corporatifs}

Banque de développement du Canada

Banque du Canada

Banque Laurentienne du Canada

Banque Nationale du Canada

Banque Royale du Canada

Banque Scotia

Bell Canada

BMO Groupe financier

Caisse de dépôt et placement du Québec

DMR

Fédération des caisses Desjardins du Québec

Gaz de France

Gaz Métro

Hydro-Québec

Industrie Canada

Investissements PSP

Ministère des Finances du Québec

Power Corporation du Canada

Raymond Chabot Grant Thornton

Rio Tinto Alcan

State Street Global Advisors

Transat A.T.

Ville de Montréal

\section{Partenaires universitaires}

École Polytechnique de Montréal

HEC Montréal

McGill University

Université Concordia

Université de Montréal

Université de Sherbrooke

Université du Québec

Université du Québec à Montréal

Université Laval

Le CIRANO collabore avec de nombreux centres et chaires de recherche universitaires dont on peut consulter la liste sur son site web.

Les cahiers de la série scientifique (CS) visent à rendre accessibles des résultats de recherche effectuée au CIRANO afin de susciter échanges et commentaires. Ces cahiers sont écrits dans le style des publications scientifiques. Les idées et les opinions émises sont sous l'unique responsabilité des auteurs et ne représentent pas nécessairement les positions du CIRANO ou de ses partenaires.

This paper presents research carried out at CIRANO and aims at encouraging discussion and comment. The observations and viewpoints expressed are the sole responsibility of the authors. They do not necessarily represent positions of CIRANO or its partners. 


\title{
Titre Emulation in Teams and Families
}

\author{
Daniel Leonard ${ }^{*}$, Ngo Van Long ${ }^{\dagger}$
}

\begin{abstract}
Résumé / Abstract
Nous présentons un modèle où la distribution de la valeur du succès d'un agent dépend non seulement de son aptitude et de son effort, mais aussi des objectifs qui lui sont fixés par le principal. L'agent choisit son effort en tenant compte de son utilité et du coût percu de l'effort. Ce coût est inversement proportionel à une 'fonction d'émulation' qui dépend des objectifs fixés à ses rivaux. Dans une première partie, nous analysons les choix d'entraineurs d'athlètes rivaux et celui de l'entraineur d'une équipe. Nous pouvons parfois ordonner leurs résultats. Une deuxième partie analyse le cas des familles qui, contrairement aux entraineurs, ne considèrent pas leurs enfants comme de parfaits substituts. Nous démontrons que souvent le processus d'émulation aboutit à des résultats contraires à une intuition naïve. Il y a maintenant deux voies distinctes pour pousser les enfants vers le succès : une voie directe par la formation, et une voie indirecte s'appuyant sur la rivalité entre frères et soeurs.
\end{abstract}

Mots clés : émulation, fixation des objectifs, relation entre un principal et des agents.

We present a model where the probability distribution over the space of an agent's achievements depends not only on her ability and effort, but also on the goals set for her. The agent chooses her effort according to her utility net of perceived cost of effort. This cost is inversely proportional to an 'emulation function' that depends on the training undertaken by rival agents. The principal also incurs costs in setting goals. In the first part of the paper we analyse the cases of coaches setting goals for rival athletes and that of a coach in charge of a team. We can sometimes rank the outcomes. In the second part of the paper we turn our attention to families where parents do not treat their children as perfect substitutes, as coaches did. We show that in many circumstances the emulation process reverses our naive intuition. There are now two distinct ways of prodding children to success: direct coaching, and emulation through sibling rivalry.

Keywords: emulation, goal setting, principal-agent relationship.

Codes JEL : D1, D23

\footnotetext{
* Flinders School of Business, Flinders University, Adelaide, Australia. Email: daniel.leonard@filnders.edu.au. $\dagger$ CIRANO and CIREQ, Department of Economics, McGill University, 855 rue Sherbrooke Ouest, Montréal, Québec, H3A 2T7, Canada. Email: ngo.long@mcgill.ca.
} 


\section{Introduction}

Emulation has long been recognized as an major force that shapes behaviour. Veblen (1924) defined emulation as "the stimulus of an invidious comparison which prompts us to outdo those with whom we are in the habit of classing ourselves." He claimed that "with the exception of the instinct for self-preservation, the propensity for emulation is probably the strongest and most alert and persistent of economic motives proper." According to Veblen "the motive that lies at the root of ownership is emulation; and the same motive of emulation continues active in the further development of institution to which it has given rise and in the development of all those features of the social structure which this institution of ownership touches." Emulation interacts with the instinct of workmanship: "Man is an agent seeking in every act an accomplishment of some concrete, objective, impersonal end. This aptitude or propensity may be called the instinct of workmanship. Whenever the circumstances of traditions of life lead to an habitual comparison of one person with another in point of efficiency, the instinct of workmanship works out in an emulative or invidious comparison of persons."

Educators have debated whether emulation should be encouraged. Rousseau was well known for his rejection of emulation. On the other hand, the use of ranking is often believed to stimulate performance. This paper explores some possible consequences of emulation. As a metaphor, we model the setting of goals for athletes by their coaches or children by their parents, who know that their charges may perform better with some suitably chosen degree of emulation.

Recently there has been some empirical evidence from economists (Mas and Moretti, 2006) that indicate that emulation does influence workers' performance.

We consider the case where the principals are interested in the actual 
performance (which may or may not exceed the set goals), rather than just achieving the goal, with success or failure as the only possible outcomes.

\section{The Model}

Goal setting has been known to be a crucial element in achieving success, be it in sports, education, academia, or in the business world. Psychologists, researchers in sports science and management science have emphasized the importance of appropriate goal setting. (See Locke and Latham (1900a, 1990b), Hardy et al. (1986), Bell (1983), Botterill (1983), Cury and Sarrazin (1993), among others.) It is generally recognized that, subject to goals being realistic, performance increases as the goals become more difficult. This is known as "the hard goal effect" . (For empirical evidence in sports, see Beggs (1990), Cury and Sarrazin (1993).

The prospect of success by an individual or a firm depend on their own efforts and abilities but might also depend on other factors, such as how they perceive their environment and others. Their probability of success, hence their performance is possibly influenced by it.. The salesperson does not operate in an isolated environment. There are other sales people in the same firm or perhaps in rival firms. They also have set targets which also influence their likelihood of success. The central premise of this paper is that the goals, or targets, for which an individual's rivals are striving have a real influence on the probability of success of that individual. Agents are aware of the targets set for other agents, and their values relative to their own target forms the basis of the process we refer to as 'emulation'.

Emulation, defined by the Webster's dictionary as "ambition or endeavor to equal or excel others (as in achievement)" is thus the main focus of the paper. It is important at this stage to clarify our use of the word 'emulation'. We use it in its common meaning. This concept has been investigateded in 
the social sciences from the time of Bentham (1811) and later Veblen ( 1924) as discussed above.

Consider an athlete or a child that faces a set goal $S$. We assume that given the pair $(E, S)$ of effort level and goal, probability that his actual performance, $A$, exceeds a given number $a$ is

$$
\operatorname{Pr}(A \geq a ; E, S)=\frac{\lambda E}{\lambda E+S^{-1} a^{2}}=\frac{1}{1+\frac{1}{\lambda E S} a^{2}}
$$

where $E \geq 0$ is his effort level, $\lambda$ denotes his ability.

The probability of reaching or exceeding a result increases with the set goal $S$ because (i) the athlete has a more positive attitude the higher is the goal, and (ii) the setting of goals is actually accompanied by a training program; the higher $S$, the better the program.

Define

$$
\alpha \equiv \frac{k}{\lambda E S}
$$

Then

$$
\operatorname{Pr}(A \geq a ; \alpha)=\frac{1}{1+\alpha a^{2}}
$$

and

$$
\operatorname{Pr}(A \leq a)=\frac{\alpha a^{2}}{1+\alpha a^{2}} \equiv G(a)
$$

where $G(a)$ is the cumulative distribution. The corresponding density function is

$$
g(a)=G^{\prime}(a)=\frac{2 \alpha a}{\left(1+\alpha a^{2}\right)^{2}}
$$

The expected performance is

$$
\begin{aligned}
\mathcal{E}(A) & =\int_{0}^{\infty} \frac{2 \alpha a}{\left(1+\alpha a^{2}\right)^{2}} d a \\
& =\left\{\frac{-a}{1+\alpha a^{2}}+\frac{1}{\sqrt{\alpha}} \arctan (\sqrt{\alpha} a)\right\}_{0}^{\infty}=\frac{\pi}{2 \sqrt{\alpha}}=\frac{\pi}{2} \sqrt{\lambda E S}
\end{aligned}
$$


Note: Expected performance increases with both effort and set goal so that it seems that setting ever higher goals will provide ever larger utility. Clearly this is not so as we now see.

\subsection{Utility of the Agent}

The agent will experience more utility, the higher her actual performance. However she has factored in the set goal $S$ and falling short of it will disappoint her, so utility is decreasing in $S$. We take

$$
U(A, S)=\frac{\rho A}{T+S}
$$

where $T>0$ and $\rho>0$ is an arbitrary scaling constant. Let $b$ be the cost of effort. The agent maximizes expected utility net of effort cost:

$$
\frac{\pi \rho}{2} \frac{1}{T+S} \sqrt{\lambda E S}-b E
$$

We normalize so that $\pi \rho / 2=1$. The first-order condition yields the agent's chosen effort level

$$
E^{*}=\frac{\lambda S}{4 b^{2}(T+S)^{2}}
$$

The function $E^{*}(S)$ is single-peaked: it reaches its maximum at $S=T$. Therefore setting ever higher goals eventually becomes counterproductive. The maximum effort exerted by the agent is thus

$$
\frac{\lambda}{16 T b^{2}}
$$

Note that it is inversely proportional to $T$. Therefore agents with a higher $T$ require a higher set goal to produce their maximum effort and that effort is lower than for an individual with a lower $T$. This leads naturally o the interpretation of $T$ as a measure of the difficulty to motivate an agent, be they an athlete or a child. 
Substitute $E^{*}$ into (2); we obtain the expected performance as a function of $S$

$$
\mathcal{E}\left(A, E^{*}(S), S\right)=\left(\frac{\pi}{2}\right) \frac{\lambda S}{2 b(T+S)}
$$

Again we see that, given $S$, a higher $T$ reduces expected performance. Also, when $S$ is set at the individual's own $T$, the expected performance is independent of $T$ but the higher $T$ individual needs a higher set goal to reach this result.

Note also, and we will come back to it, that 3indicates that optimal effort is inversely proprtional to the square of the unit cost of effort, $b$.

\subsection{The Principal's Objective}

The coach chooses $S$ to maximize the expected performance net of training cost $\omega S$

$$
\left(\frac{\pi}{2}\right) \frac{\lambda S}{2 b(T+S)}-\omega S=\left(\frac{\pi}{2}\right) \frac{\lambda}{2 b\left(1+S^{-1} T\right)}-\omega S
$$

Define

$$
w=\frac{2 \omega}{\pi}
$$

The first-order condition for the coach's problem is

$$
S^{*}=T\left[\sqrt{\frac{\lambda}{2 b w T}}-1\right]=\sqrt{\frac{\lambda T}{2 b w}}-T
$$

\subsection{Emulation}

We have argued earlier, and it is the central premise of this paper, that emulation ( the goal setting of rivals or siblings) has a positive influence on an agent's behaviour. The simplest way to model this is to assume it lowers the agent's cost of effort. In practice this can take many forms, such as a fellow PhD student's aim to finish their thesis by December fortifying 
another student's resolve to work on wekends, a boy's concentration's on his piano lessons being made somewhat more palatable because his little sister now has violin lessons three imes a week. Here we simply assume that effort cost is a decreasing function of the rival's goal

$$
\frac{1}{2 b}=F\left(S_{2}\right)
$$

where $F^{\prime}\left(S_{2}\right)>0$. This means that an increase in $S_{2}$ decreases $b$. Emulation lowers effort cost.

Consider the situation where there are two agents and two principals: two principals coaching two rival athletes.

Coach $i$ takes $S_{j}$ as given. The first-order condition with respect to $S_{i}$ is

$$
S_{i}=\sqrt{\frac{F\left(S_{j}\right) \lambda T}{w}}-T
$$

Take the linear case:

$$
F\left(S_{j}\right)=\theta+\sigma S_{j}
$$

The first-order condition for coach 1 is

$$
S_{1}^{*}=\sqrt{\frac{\lambda_{1} T_{1}\left(\theta+\sigma S_{2}\right)}{w}}-T_{1}=\sqrt{\frac{\lambda_{1} T_{1}}{\frac{w}{\left(\theta+\sigma S_{2}\right)}}}-T_{1}
$$

Or,

$$
S_{i}^{*}=\max \left\{0, \sqrt{\frac{\lambda_{i} T_{i}\left(\theta+\sigma S_{j}\right)}{w}}-T_{i}\right\}
$$

This yields a positively-sloped and concave reaction function $S_{i}^{*}=R_{i}\left(S_{j}\right)$ when $S_{i}^{*}>0$. Note that when $S_{j}=0$ then $S_{i}^{*}>0$ if and only if

$$
\sqrt{\frac{\lambda_{i} T_{i} \theta}{w}}>T_{i} \text {, or } \lambda_{i} \theta>w T_{i}
$$

Proposition 1: If condition (8) holds then there exists a unique equilibrium $\left(S_{1}^{N}, S_{2}^{N}\right)>(0,0)$. 
(Proof: $R_{i}(0)>0$ and $R_{i}^{\prime}>0, R_{i}^{\prime \prime}<0$.So, in a diagram with $S_{2}$ measured along the horizontal axis and $S_{1}$ along the vertical axis, the reaction curve $S_{1}=R_{1}\left(S_{2}\right)$ is concave with $R_{1}(0)>0$, while the other reaction curve has the convex shape, with $R_{2}(0)>0$. Therefore there is a unique intersection in the positive orthant). This requires agent $i^{\prime} s$ ability to be large enough compared with the difficulty of training her, from hers and her coach's point of'view, $w T_{i}$.

\section{Teamwork}

Now consider the situation where there is only one coach and two athletes. The coach is interested in the overall performance of the team, e. g. how many medals they bring back. He maximizes the sum of net (of his own efforts) performances, that is

$$
\frac{\lambda_{1} S_{1} F\left(S_{2}\right)}{T_{1}+S_{1}}+\frac{\lambda_{2} S_{2} F\left(S_{1}\right)}{T_{2}+S_{2}}-w\left(S_{1}+S_{2}\right)
$$

Again, assume

$$
F\left(S_{j}\right)=\theta+\sigma S_{j}
$$

The first-order condition with respect to $S_{1}$ is

$$
\frac{\lambda_{1} F\left(S_{2}\right)}{\left(T_{1}+S_{1}\right)^{2}}=w-\frac{\lambda_{2} S_{2} \sigma}{\left(T_{2}+S_{2}\right)}
$$

Hence

$$
\frac{\lambda_{1}}{\left(T_{1}+S_{1}\right)^{2}}=\frac{w}{\theta+\sigma S_{2}}-\frac{\lambda_{2} S_{2} \sigma}{\left(T_{2}+S_{2}\right)\left(\theta+\sigma S_{2}\right)}
$$

and thus

$$
S_{1}=\sqrt{\frac{\lambda_{1} T_{1}}{\frac{w}{\theta+\sigma S_{2}}-\frac{\lambda_{2} S_{2} \sigma}{\left(T_{2}+S_{2}\right)\left(\theta+\sigma S_{2}\right)}}}-T_{1} \equiv r_{1}\left(S_{2}\right)
$$

In a diagram with $S_{2}$ measured along the horizontal axis and $S_{1}$ along the vertical axis, the curve $r_{1}\left(S_{2}\right)$ lies above the curve $R_{1}\left(S_{2}\right)$. 
Similarly, the first-order condition with respect to $S_{2}$ yields

$$
S_{2}=\sqrt{\frac{\lambda_{2} T_{2}}{\frac{w}{\theta+\sigma S_{1}}-\frac{\lambda_{1} S_{1} \sigma}{\left(T_{1}+S_{1}\right)\left(\theta+\sigma S_{1}\right)}}}-T_{2} \equiv r_{2}\left(S_{1}\right)
$$

It follows that the intersection of the two curves $S_{1}=r_{1}\left(S_{2}\right)$ and $S_{2}=$ $r_{2}\left(S_{1}\right)$ must be to the North-East of the intersection of two curves $S_{1}^{*}=$ $R_{1}\left(S_{2}\right)$ and $S_{2}^{*}=R_{2}\left(S_{1}\right)$. This shows that:

Proposition 2: The coach's optimal values of $S_{1}$ and $S_{2}$ exceed the Nash equilibrium $\left(S_{1}^{N}, S_{2}^{N}\right)$. We have shown that, left to his own devices, a coach will set higher goals, hence devote more resources to training athletes if he is not competing against another, but managing a team. The inclusion of emulation has stood on its head the old adage tha competition is beneficial for everything and everyone.

\section{Family Decisions}

Suppose now that the situation is that of a family trying to decide on an education policy for their children. It is not just a matter of how much to spend on school fees and college tuition. This is to a large extent determined by their financial circumstances. Parents have a deeper responsibility. They must set goals and boundaries for their children. Their guidance will make a real difference to their children's acheivements. It shapes their expectations of happiness and success. It thus affects how they feel. All children are different, even in the same family (One could speculate that one of the main objectives of families is to make their children more alike, but this is not the object of our enquiry here.)

Therefore some of the pertinent questions may be:

How are children of different abilities treated?

How are children who may be easier or harder to motivate treated? 
How do parents with different resources cope? Is there a pattern that shows parents of different means react differently to the characteristics of their children?

What is the influence of emulation in all that?

What consequences does the parents' attitude towards the children have on on they are treated and on how they perform?

We attempt to answer these questions in the framework of our model.

\subsection{Families are Different}

Parents have preferences over their childrens' achievements. Their own utility depends on it. They also have constraints on how they deal with the demands of settings goals and boundaries for them. As every parent knows, it is not simply a matter of deciding how far Junior will go to school, it must also be explained, talked about; resources must be used to make the point and it all takes a psychic toll on the parents. Most parentslove their children and care for them, but it does have costs, and the costs we are focusing on here are that of setting goals for children. It does take many forms, financial, psychological and time constraints.

In the framework of this model parents maximize a combination of their children's expected performances, subject to the cost of enforcing these goals for them, not exceeding a 'budget' $Y$.

This can be justified by assuming strong separability between children's education and more mundane matters, in the paents' utility.

Parents also have preferences over their childrens' achievements. We use a simple Cobb-Douglas function to represent these. The reason why we have chosen this function is because, although parents my not treat their children in the same manner, in the end parents would not be satisfied if one child acheived a very low performance. When we modelled the performance 
of a team in the previous section, we used a simple additive form. What mattered was the performance of the team, no matter who acheived it (how many medals did the swimming team take home for instance). We argue that parents take a more individual approach and favour a more even distribution of performances, hence the Cobb-Douglas to reflect the fact that a very poor performance by one of the children would severely affect the parents' utility.

Parents choose $S_{1}$ and $S_{2}$ to maximize

$$
V\left(S_{1}, S_{2}\right)=\left[E\left(A_{1}\right)\right]^{\varepsilon_{1}} \cdot\left[E\left(A_{2}\right)\right]^{\varepsilon_{2}} \quad, \quad \varepsilon_{i}>0
$$

subject to

$$
w\left(S_{1}+S_{2}\right)=Y
$$

or

$$
S_{1}+S_{2}=y \text {, where } y \equiv Y / w
$$

The maximand is

$$
\epsilon_{1} \operatorname{Ln} \frac{\lambda_{1} S_{1} F\left(S_{2}\right)}{T_{1}+S_{1}}+\epsilon_{2} \operatorname{Ln} \frac{\lambda_{2} S_{2} F\left(S_{1}\right)}{T_{2}+S_{2}}
$$

The first order condition is

$$
\frac{\epsilon_{1}}{S_{1}}-\frac{\epsilon_{1}}{S_{1}+T_{1}}+\frac{\epsilon_{2} F^{\prime}\left(S_{1}\right)}{F\left(S_{1}\right)}=\frac{\epsilon_{2}}{S_{2}}-\frac{\epsilon_{2}}{S_{2}+T_{2}}+\frac{\epsilon_{1} F^{\prime}\left(S_{2}\right)}{F\left(S_{2}\right)}
$$

(a) If $\epsilon_{1}=\epsilon_{2}$, the abilities of the children are of no consequence to the actions of the parents - not their satisfaction.

(b) If parents prefer one child over the other, we could represent that by letting $\epsilon_{1}$ and $\epsilon_{2}$ be different while $\lambda_{1}$ and $\lambda_{2}$, as well as $T_{1}$ and $T_{2}$ are the same (twins).

(c) If parents prefer the more able child, we could represent that by letting $\epsilon_{1}$ and $\epsilon_{2}$ be proportional to $\lambda_{1}$ and $\lambda_{2}$, respectively. 
(d) If parents prefer the less able child, we could represent that by letting $\epsilon_{1}$ and $\epsilon_{2}$ be proportional to $\lambda_{2}$ and $\lambda_{1}$, respectively.

(e) Parents may also have prefernces over the relative difficulties of motivating their children and so may take $\epsilon_{1}$ and $\epsilon_{2}$ to be proportional to $T_{2}$ and $T_{1}$, respectively.

(f) Conversely they may favour the child who is harder to motivate and take $\epsilon_{1}$ and $\epsilon_{2}$ to be proportional to $T_{1}$ and $T_{2}$, respectively.

We assume that the emulation function takes the form

$$
F\left(S_{i}\right)=\left(S_{i}\right)^{\beta}, 0<\beta<1
$$

A multiplicative constant in the above formulation would not measure the strength of the emulative process, as it drops out of the calculations. The size of $\beta$ however is such an indicator. When $\beta$ is very small, close to zero, the value of $S_{i}$ has little influence on $F\left(S_{i}\right)$ as the function is almost constant for all values of $S_{i}$ that are not too small. On the contrary, when $\beta$ is close to 1 , the emulation factor is almost proportional to $S_{i}$. Therefore we interpret $\beta$ as the sensitivity of one child to the goal set for their sibling, the strength of the emulation process.

Under this formulation the first-order condition is

$$
\frac{\epsilon_{1}+\beta \epsilon_{2}}{S_{1}}-\frac{\epsilon_{1}}{S_{1}+T_{1}}=\frac{\epsilon_{2}+\beta \epsilon_{1}}{S_{2}}-\frac{\epsilon_{2}}{S_{2}+T_{2}}
$$

As the absolute size of $\epsilon_{1}$ and $\epsilon_{2}$ is irrelevant, we can set $\epsilon_{1}+\epsilon_{2}=1$ or any constant.

The details of calculations are set out in the appendix.

(a) If both children are willing to work equally hard, parents will set identical goals for them, irrespective of their individual abilities. Otherwise they will set the higher goal for the more difficult child. Furthermore, the 
more difficult it is to motivate one child, the lower the goal set for their sibling.

(b) If favouritism is arbitrary ( letting $\epsilon_{1}=1$, without loss of generality and $\varepsilon_{2}>1, T_{1}=T_{2}=T$ and $\left.\lambda_{1}=\lambda_{2}\right)$

$$
\frac{1+\beta \epsilon_{2}}{S_{1}}-\frac{1}{S_{1}+T}=\frac{\epsilon_{2}+\beta \epsilon_{1}}{S_{2}}-\frac{\epsilon_{2}}{S_{2}+T}
$$

(c) If $\epsilon_{1}$ and $\epsilon_{2}$ are proportional to $\lambda_{1}$ and $\lambda_{2}$, respectively, the first-order condition becomes

$$
\frac{\lambda_{1}+\beta \lambda_{2}}{S_{1}}-\frac{\lambda_{1}}{S_{1}+T_{1}}=\frac{\lambda_{2}+\beta \lambda_{1}}{S_{2}}-\frac{\lambda_{2}}{S_{2}+T_{2}}
$$

(d) Similarly if, conversely, $\epsilon_{1}$ and $\epsilon_{2}$ were proportional to $\lambda_{2}$ and $\lambda_{1}$, respectively, we would have

$$
\frac{\lambda_{2}+\beta \lambda_{1}}{S_{1}}-\frac{\lambda_{2}}{S_{1}+T_{1}}=\frac{\lambda_{1}+\beta \lambda_{2}}{S_{2}}-\frac{\lambda_{1}}{S_{2}+T_{2}}
$$

(e) Parents may also have preferences over the relative difficulty of motivating their children. If they favour the child who is harder to motivate we can take

$$
\epsilon_{1}=\frac{T_{1}}{T_{1}+T_{2}}, \quad \epsilon_{2}=\frac{T_{2}}{T_{1}+T_{2}} .
$$

Then the first-order condition is

$$
\frac{T_{1}+\beta T_{2}}{S_{1}}-\frac{T_{1}}{S_{1}+T_{1}}=\frac{T_{2}+\beta T_{1}}{S_{2}}-\frac{T_{2}}{S_{2}+T_{2}}
$$

(f) If willingness to work hard is foremost in the parents'minds; for instance if they favour the more willing child we can take

$$
\epsilon_{1}=\frac{T_{2}}{T_{1}+T_{2}}, \quad \epsilon_{2}=\frac{T_{1}}{T_{1}+T_{2}}
$$


Then

$$
\frac{T_{2}+\beta T_{1}}{S_{1}}-\frac{T_{2}}{S_{1}+T_{1}}=\frac{T_{1}+\beta T_{2}}{S_{2}}-\frac{T_{1}}{S_{2}+T_{2}}
$$

These characterizations of outcomes enable us to carry out comparative statics experiments in an attempt to answer the queries raised above.

\section{Analysis}

We use the following notation in the Analysis.

$T \equiv \frac{T_{1}+T_{2}}{2}, x \equiv \frac{\lambda_{2}}{\lambda_{1}}, y^{c} \equiv 2 T\left(\frac{1-\beta}{\beta}\right), y \equiv n y^{c}, t \equiv \frac{T_{2}}{T_{1}}, T_{1}=\frac{2 T}{1+t} T_{2}=\frac{2 t T}{1+t}$

REMARK. We must comment on the critical 'educational budget' $y^{c} \equiv$ $2 T\left(\frac{1-\beta}{\beta}\right)$. When emulation is negligible and $\beta$ is close to $0, y^{c}$ is very large and it is likely that the actual budget is below the critical value. When emulation is strong and $\beta$ is close to $1, y^{c}$ is very small and it is almost certain that the actual budget is above the critical value. Recall that a goal set at $T$, in the absence of emulation, induces the largest possible effort, so that the values of $S, y$ and $T$ are on similar scales. The critical income value $y^{c}$ is the budget above which emulation takes on a stronger, possibly determinant role; we shall see that it yields results counterintuitive to a 'naive' understanding that doesn't factor in the consequences of emulation.

The optimum values are denoted by $S_{1}^{*}$ and $S_{2}^{*}$. The first-order condition is $\quad V_{1}-V_{2}=0$, where

$$
V_{1} \equiv \frac{\epsilon_{1}+\beta \epsilon_{2}}{S_{1}}-\frac{\epsilon_{1}}{S_{1}+T_{1}} \quad \text { and } \quad V_{2} \equiv \frac{\epsilon_{2}+\beta \epsilon_{1}}{S_{2}}-\frac{\epsilon_{2}}{S_{2}+T_{2}}
$$

The derivatives of $V_{1}-V_{2}$ with respect to $S_{1}$ and $S_{2}$ are negative and positive, respectively, because of the second-order condition. 
We use the following method to ascertain which goal is larger at the optimum.

We evaluate $V_{1}$ and $V_{2}$ at $(S, S)$ (Note that $S=y / 2$ then). $V_{i}(S, S)>$ $V_{j}(S, S)$ implies $S_{i}^{*}>S_{j}^{*}$ because $V_{1}=V_{2}$ at the optimum and $S_{1}=S_{2}$ along the constraint.

(a) $\epsilon_{1}=\epsilon_{2}$. Suppose $T_{2}>T_{1}$ then $V_{2}(S, S)>V_{1}(S, S)$ therefore $S_{2}^{*}>S_{1}^{*}$. $d\left(V_{1}-V_{2}\right) / d T_{1}>0$ and $d\left(V_{1}-V_{2}\right) / d T_{2}<0$, hence $d S_{1} / d T_{2}<0$ and $d S_{2} / d T_{2}>0$.

(b) Here we take $\varepsilon_{1}=1, \varepsilon_{2}>1, T_{1}=T_{2}=T$ and $\lambda_{1}=\lambda_{2}$. This is the case of a preferred twin.

The first-order condition is

$$
\frac{1+\beta \varepsilon_{2}}{S_{1}}-\frac{1}{S_{1}+T}-\left[\frac{\varepsilon_{2}+\beta}{S_{2}}-\frac{\varepsilon_{2}}{S_{2}+T}\right]=0
$$

It is straightforward to show, using the method outlined above, that $V_{2} \geq$ $V_{1}$ requires $y \leq y^{c}$ and implies $S_{2}^{*} \geq S_{1}^{*}$. Conversely $y \geq y^{c}$ implies $S_{2}^{*} \leq S_{1}^{*}$. Therefore when the budget is below the critical value we observe the parents lavishing more care, or coaching, on the preferred twin. However when the educational budget is high, the situation is reversed. The explanation is this. Reversal is more likely to occur the stronger the influence of emulation is because $y^{c}$ is small then. in this situation the favouritism shown by parents for child number 2 manifests itself by a higher goal set for child number 1, so as to stimulate the preferred twin by lowering the cost of that child's effort. See equations4 and 5. It is worth noting that when emulation is moderate, say $\beta=0.5$, the critical income is $2 T$, just enough to stimulate both children to maximum effort in the absence of emualtion.

A low income ( hence likely a weak emulation process) implies the favourite child is set a higher goal but at a high income (strong emulation likely) their less favoured sibling is set a higher goal in order to lower the cost of effort of the favourite. The reason why this apparent reversal of interest occurs 
is that at higher income parents have exhausted the effectiveness of direct coaching on the 'chosen one' and resort to indirect influence through emulation by additional expense on the other child. This reversal (because of high income) is more likely to occur when emulation forces are strong.

It is also possible to find bounds on the differences between $S_{2}^{*}$ and $S_{1}^{*}$.

Evaluating $V_{1}$ and $V_{2}$ at $S_{2}=\varepsilon_{2} S_{1}$,we find

$$
V_{1}=\frac{1+\beta \varepsilon_{2}}{S_{1}}-\frac{1}{S_{1}+T},{ }^{\prime} V_{2}=\frac{\varepsilon_{2}+\beta}{\epsilon_{2} S_{1}}-\frac{\varepsilon_{2}}{\epsilon_{2} S_{1}+T} \text { hence } V_{2}<V_{1} \text { and } S_{2}^{*}<\varepsilon_{2} S_{1}^{*} \text {. }
$$

Conversely, evaluating $V_{1}$ and $V_{2}$ at $S_{1}=\varepsilon_{2} S_{2}$, we find in a similar fashion that $S_{1}^{*}<\varepsilon_{2} S_{2}^{*}$.'neither goal can exceed the other by a factor of $\varepsilon_{2}$ or more generally by the ratio $\frac{\varepsilon_{2}}{\varepsilon_{1}}$.

Consider now the influence of the strgth of preferences of parents.

The first-order condition can be written as

$$
\varepsilon_{2}\left[\frac{1}{S_{2}+T}-\frac{1}{S_{2}}+\frac{\beta}{S_{1}}\right]-\left[\frac{1}{S_{1}+T}-\frac{1}{S_{1}}+\frac{\beta}{S_{2}}\right]=0
$$

The partial derivative of the first-order condition with respect to $\varepsilon_{2}$ is the first bracket, which has the same sign as the second bracket. These signs are those of

$$
\left[\beta S_{2}\left(S_{2}+T\right)-T S_{1}\right] \text { and }\left[\beta S_{1}\left(S_{1}+T\right)-T S_{1}\right] \text { respectiveely }
$$

. hence it also the sign of their sum

$$
\left[\beta\left(S_{1}^{2}+S_{2}^{2}\right)+T y(\beta-1)\right] \text { or }\left[\beta\left(\left(S_{1}+S_{2}\right)^{2}-2 S_{1} S_{2}\right)-T y(\beta-1)\right] .
$$

This last expression has the sign of $\left[y^{2}-2 S_{1} S_{2}-t T(1-\beta) / \beta\right]$, or 


$$
\begin{gathered}
{\left[y-T\left(\frac{1-\beta}{\beta}\right)\right]^{2}-T^{2}(1-\beta)^{2} / 4 \beta^{2}-2 S_{1} S_{2} \text { and finally }} \\
{\left[T\left(\frac{1-\beta}{2 \beta}\right)-y\right]^{2}-\left[T\left(\frac{1-\beta}{2 \beta}\right)\right]^{2}-2 S_{1} S_{2}<0 .}
\end{gathered}
$$

Therefore

$$
\frac{d S_{2}^{*}}{d \varepsilon_{2}}>0
$$

The more favoured one child is, the higher the goal set for that child, everything else equal. However, if income is high (emulation is strong), that goal is still lower than that of the other twin.

The influence of $T$ is not determinate. The partial derivative of the firstorder condition with respect to $T$ has the sign of $\left[\left(S_{2}+T\right)-\sqrt{\varepsilon_{2}}\left(S_{1}+T\right)\right]$. If $S_{1}=S_{2}=S$, that sign is negative (recall $\varepsilon_{2}>1$ here.) If $S_{1}=\sqrt{\varepsilon_{2}} S_{2}$ or if $S_{2}=\sqrt{\varepsilon_{2}} S_{1}$, the sign is also negative. Only if $S_{2}$ is very large compared to $S_{1}$ and $T$ ( and recall that $S_{2}^{*}<\varepsilon_{2} S_{1}^{*}$ ) can the derivative be positive. In all our examples it is negative and we take this to be the 'normal' result.

$$
\text { Therefore 'normally' } \frac{d S_{2}^{*}}{d T}>0 \text { and } \frac{d S_{1}^{*}}{d T}<0 \text {. }
$$

In this context, for fixed $y$, the most favoured child is set a higher goal when the twins are harder to motivate. The reverse is true when the twins are keen to excel. It seems that the difficulty of educating these children exacerbates their different treatment; in this case unambiguously towards the favoured twin. The turning point, in the above diagram, corresponds to the critical value associated with reversal and is higher, the larger $\beta$ is, or the stronger emulation works.

(c) The first-order condition is

$$
\frac{\lambda_{1}+\beta \lambda_{2}}{S_{1}}-\frac{\lambda_{1}}{S_{1}+T_{1}}=\frac{\lambda_{2}+\beta \lambda_{1}}{S_{2}}-\frac{\lambda_{2}}{S_{2}+T_{2}}
$$




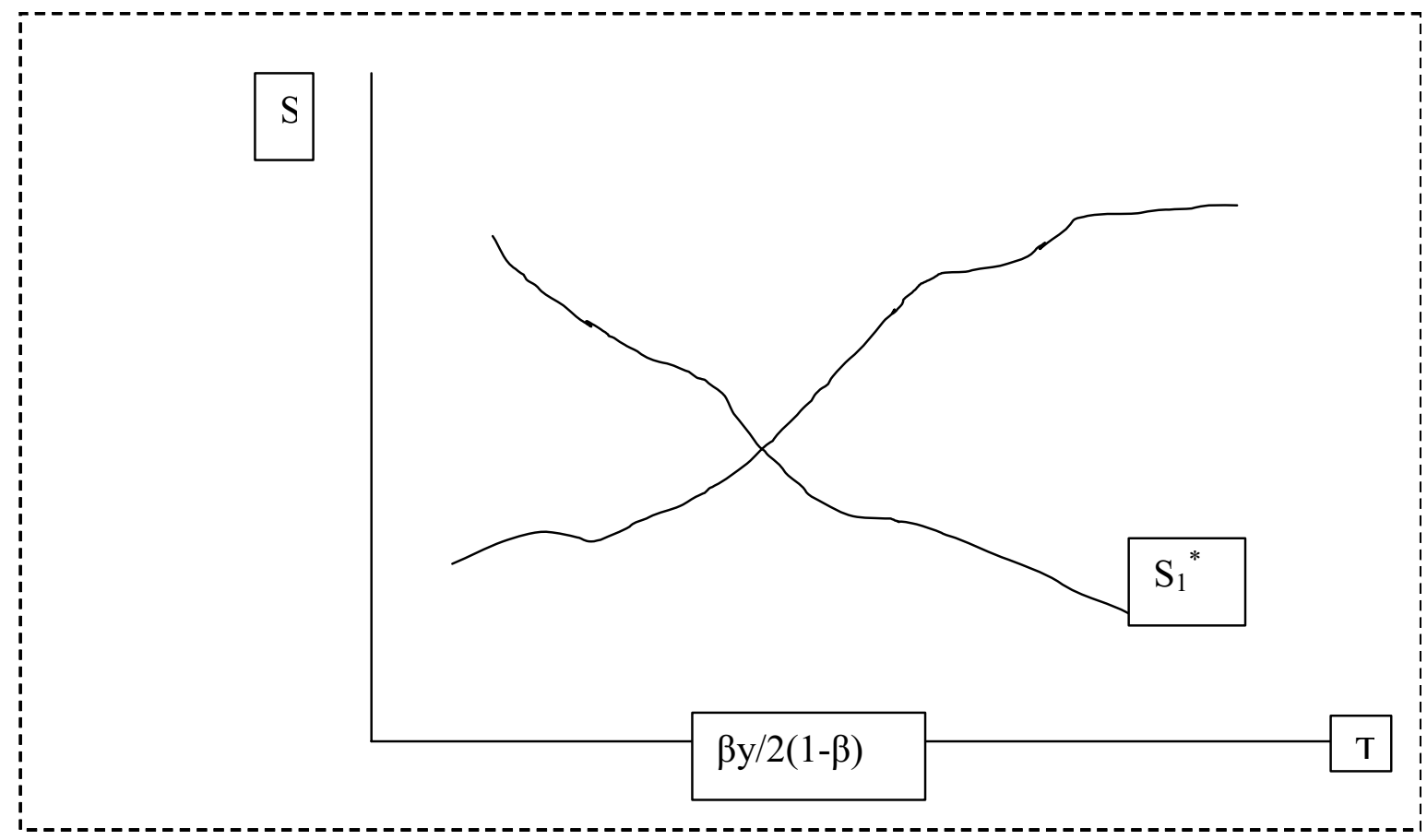

First consider the case where $T_{1}=T_{2}=T$ and $x>1$.

At $(S, S), V_{2} \leq V_{1}$ can be written as $\frac{1+\beta x}{S}-\frac{1}{S+T} \geq \frac{x+\beta}{S}-\frac{x}{S+T}$ wich is true if and only if $y \geq y^{c}-$ Recall $S=y / 2$.

Therefore when $t=1$ and $x>1, S_{2}^{*}<S_{1}^{*}$ if and only if $y>y^{c}$.By continuity this also true for $t$ near 1 .

In order to trace the boundary between the regions where $S_{2}^{*}<S_{1}^{*}$ and $S_{2}^{*}>S_{1}^{*}$, in the $(x, t)$ space we use the first-order condition evaluated at $(S, S), \frac{1+\beta x}{S}-\frac{1}{S+T_{1}}=\frac{x+\beta}{S}-\frac{x}{S+T_{2}}$. We obtain for the boundary $x=\frac{A^{-1}-\beta}{B^{-1}-\beta}$, where $A=1+n\left(\frac{1-\beta}{\beta}\right)(1+t), B=1+n\left(\frac{1-\beta}{\beta}\right)\left(\frac{1+t}{t}\right)$

This boundary can be plotted for selected values of $\beta$ and $n$. It is possible that the numerator and the denominator are of different signs, in which case one of the goals is always above the other. It is easy to show that, 


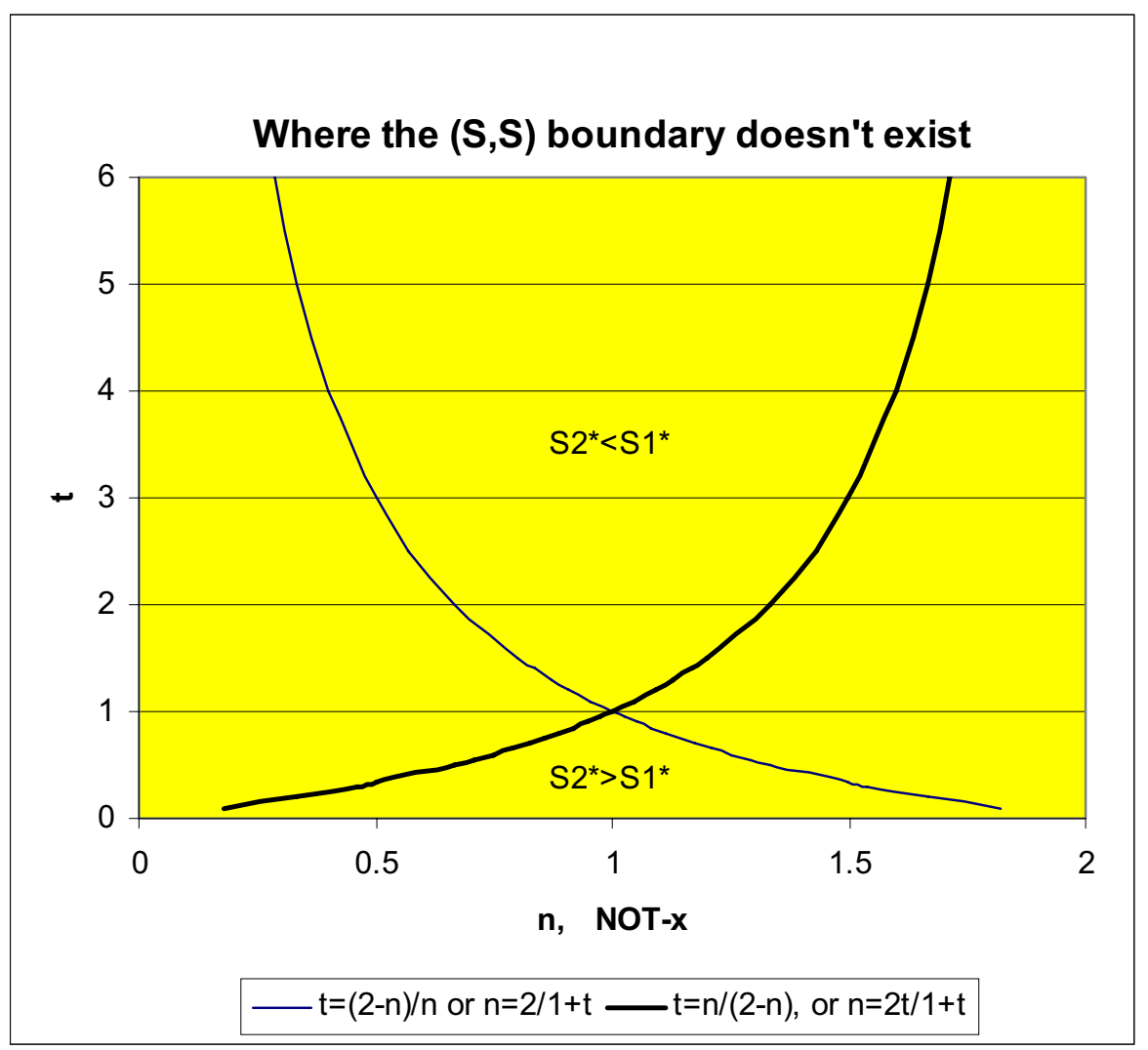

independently of the value of $\beta$,

The numerator has the sign of $n-\frac{2}{1+t}$ and the denominator that of $n-\frac{2 t}{1+t}$

From this result we can draw the following diagram that indicates the relative values of $T_{1}$ and $T_{2}$ and $y$ (relative to $T$ ) where one of the goals always dominates. This happens when $y$ is not too far from $y^{c}$ and $T_{1}$ and $T_{2}$ not too close together.

The boundary rotates anti-clockwise as income increases. When $y$ is close to $y^{c}$ the boundary is almost a straight line at $t=1$ and valid for a very small interval of $t$ values, as expected from Figure 1 above. 


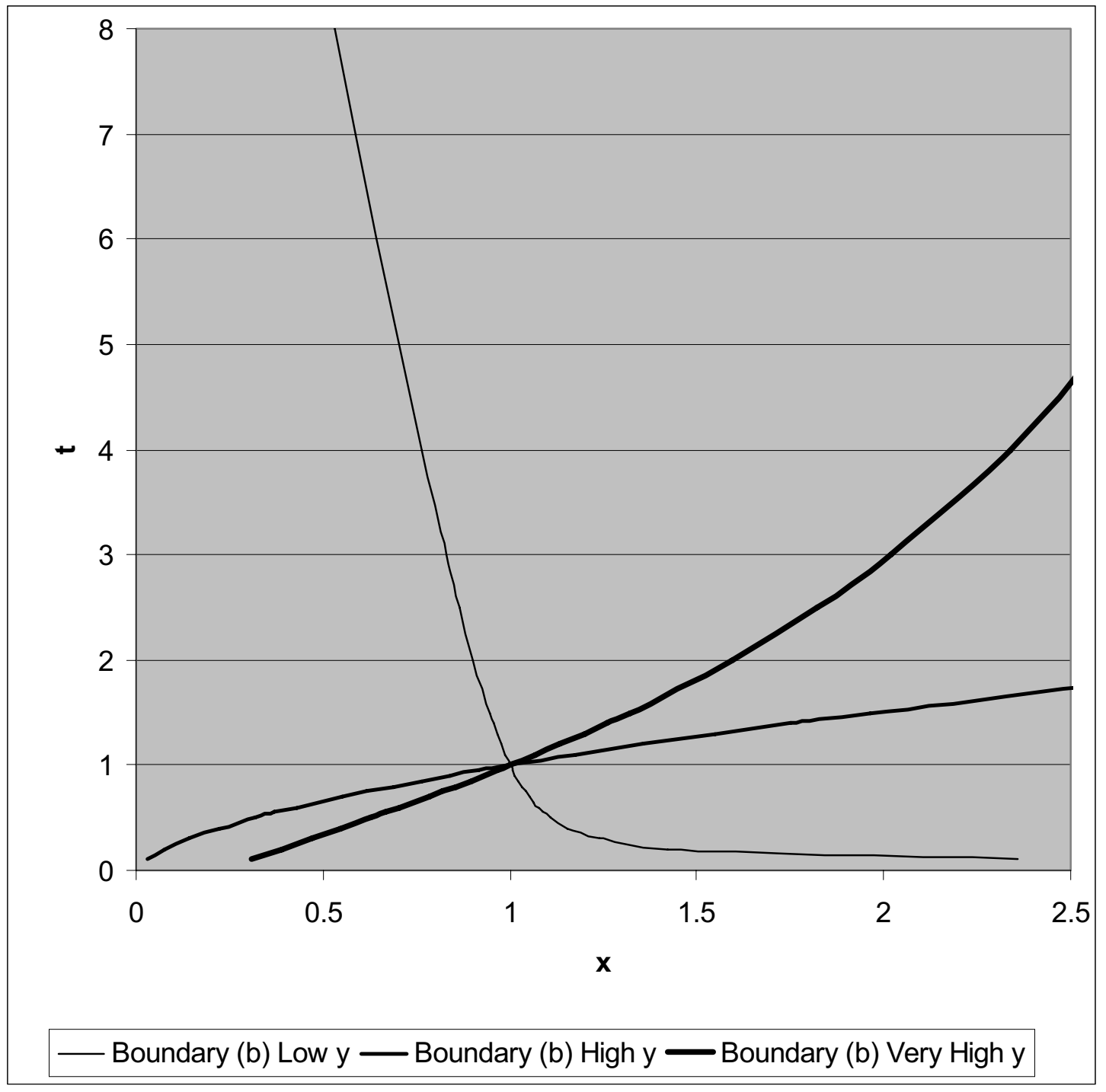




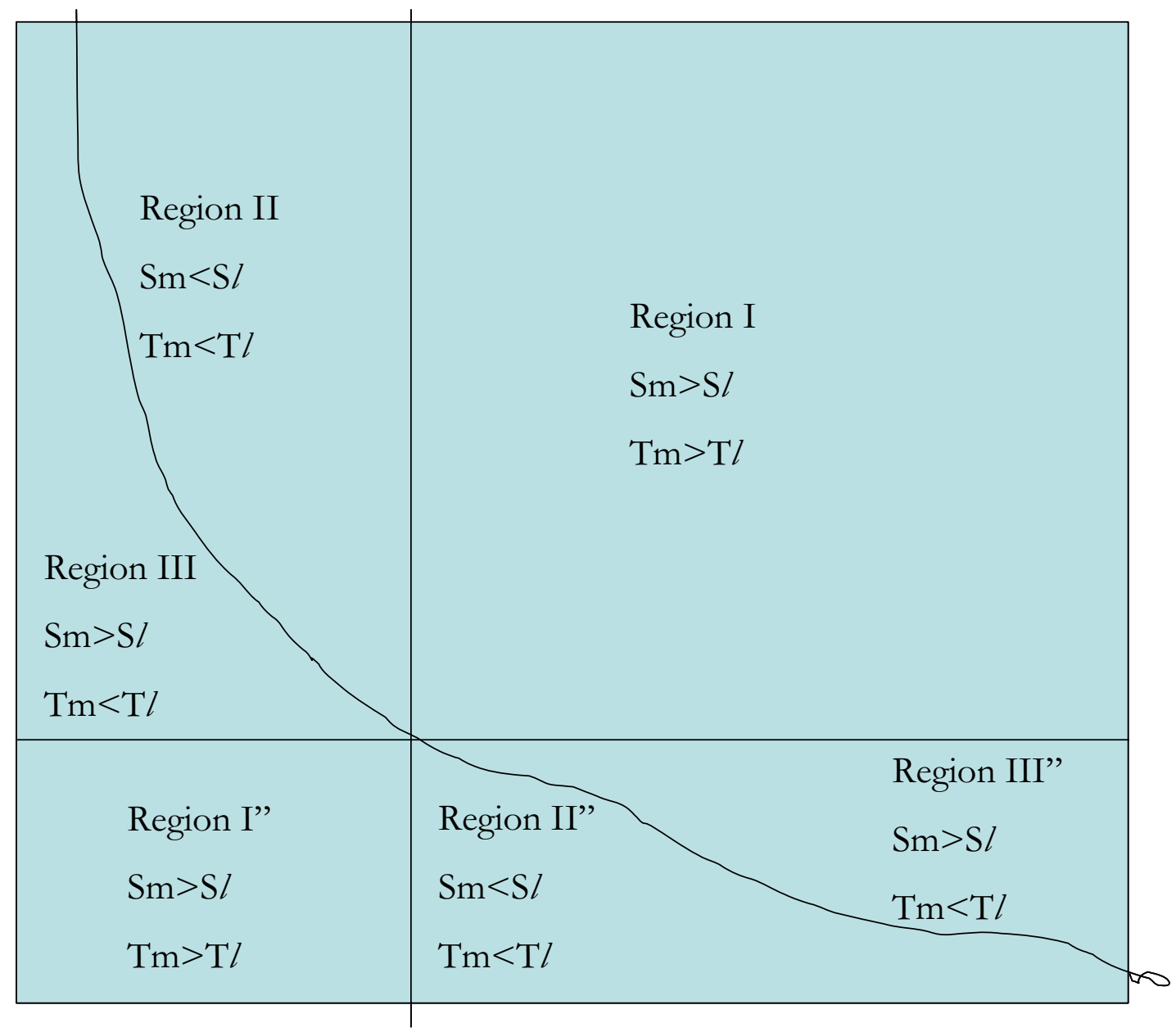

In the $(x, t)$ space we illustrate how the $S_{1}^{*}=S_{2}^{*}$ boundary varies with income $y$.

The boundary rotates anti-clockwise as income increases. When $y$ is close to $y^{c}$ the boundary is almost a straight line at $t=1$ and valid for a very small interval of $t$ values, as expected from Figure 1 above.

In order to understand the partitionning of the $(x, t)$ space let us rethink our description of 'high income'. It means $y>y^{c}$. This is more likely to occur when emulation is strong because in that case $y^{c}$ is small. So let us now refer 
to situations of 'high income' as situations of 'strong emulation'. We have depicted the case of weak emulation (low income) in Fig. ? Six regions are identified. The notations $S_{m}^{*}$ and $S_{l}^{*}$ refer to more gifted child and less gifted, respectively, as do $T_{m}$ and $T_{l}$. In region I child 2 is more gifted and $S_{m}^{*}>S_{l}^{*}$; also $T_{2}>T_{1}$ hence $T_{m}>T_{l}$. In region I" child 1 is more gifted and $S_{m}^{*}>S_{l}^{*}$ still; also $T_{1}>T_{2}$ hence $T_{m}>T_{l}$ as well. In region II for instance $\lambda_{1}>\lambda_{2}$ and $T_{2}>T_{1}$ as well as $S_{2}^{*}>S_{1}^{*}$, so we have $S_{m}^{*}<S_{l}^{*}$ and $T_{m}<T_{l}$. Similar relations are deduced from Figure ? for all six regions of Fig. ?. First note that regions I and I", II and II" etc... are homeomorphic in the terminology of 'more gifted' and 'less gifted'; their definitions are identical, as can be seen on the diagram. The terminology of child 1 and child 2, while useful in the calculations, must now give way to the more relevant distinction of ability. The interpretation of the results is as follows. When emulation is weak a child who is both more gifted and more difficult will attract more coaching (region I); this is expected when parents' preferences follow ability. This will hold true even if the more gifted child is a little easier to motivate. Only if one child is only slightly more gifted and much more difficult to motivate, will parents set him or her a lower goal (region II). They are then using the other child to lower the cost of effort to the more gifted and preferred one through emulation. This, in the $(x, t)$ space seems to happen less frequently.

We now turn to the high budget (strong emulation) case; see Fig. ?. The boundary has rotated counter-clock wise, from the low budget situation and regions III and III" have disappeared when the boundary moved into the $t=1$ line. Regions IV and IV" have emerged. They, and regions II and II", now dominate the diagram. When the emulation process is much stronger (high budget), the situation is reversed: parents use their considerable budget to help the favoured child indirectly, by lowering that child's effort cost through emulation and coaxing him or her into higher effort by coaching the less favoured child more. As remarked earlier, we could also view the situa- 
tion as one where parents have exhuasted their direct influence on the more gifted child through additional coaching and now revert to indiect coaxing by lowering the child's effort cost through emulation.

(d) Here we suppose that parents favour the less gifted child.

The first-order condition is

$$
\frac{\lambda_{2}+\beta \lambda_{1}}{S_{1}}-\frac{\lambda_{2}}{S_{1}+T_{1}}=\frac{\lambda_{1}+\beta \lambda_{2}}{S_{2}}-\frac{\lambda_{1}}{S_{2}+T_{2}}
$$

We proceed as in case (c).

The expression for the boundary is

$$
x=\frac{(1-\beta)-\left(1+(B-1)^{-1}\right)^{-1}}{(1-\beta)-\left(1+(A-1)^{-1}\right)^{-1}} \text { where } \mathrm{A} \text { and } \mathrm{B} \text { are as above. }
$$

It is easy to show that, independently of the value of $\beta$, the numerator and the denominator are of the signs of

$$
\frac{2 t}{1+t}-n \text { and of } \frac{2}{1+t}-n, \text { respectively. }
$$

Therefore the zones in $(n, t)$ space where $S_{2}^{*}<S_{1}^{*}$ and $S_{2}^{*}>S_{1}^{*}$ are inverted compared to case (c).

The boundary rotates clockwise as income increases. When $y$ is close to $y^{c}$ the boundary is almost a straight line at $t=1$ and valid for a very small interval of $t$ values, as expected from Figure 1 above.

Now parents favour the child with the lower ability. An analysis of the diagram along the lines of what was done in case (c) reveals a startling fact. When emulation is weak (low income) in case (d) the broad shape of the boundary and the exact definition of the regions match the results of case (c) when emulation is strong. Conversely, strong emulation with preference for the less able child match the results of weak emulation with preference 


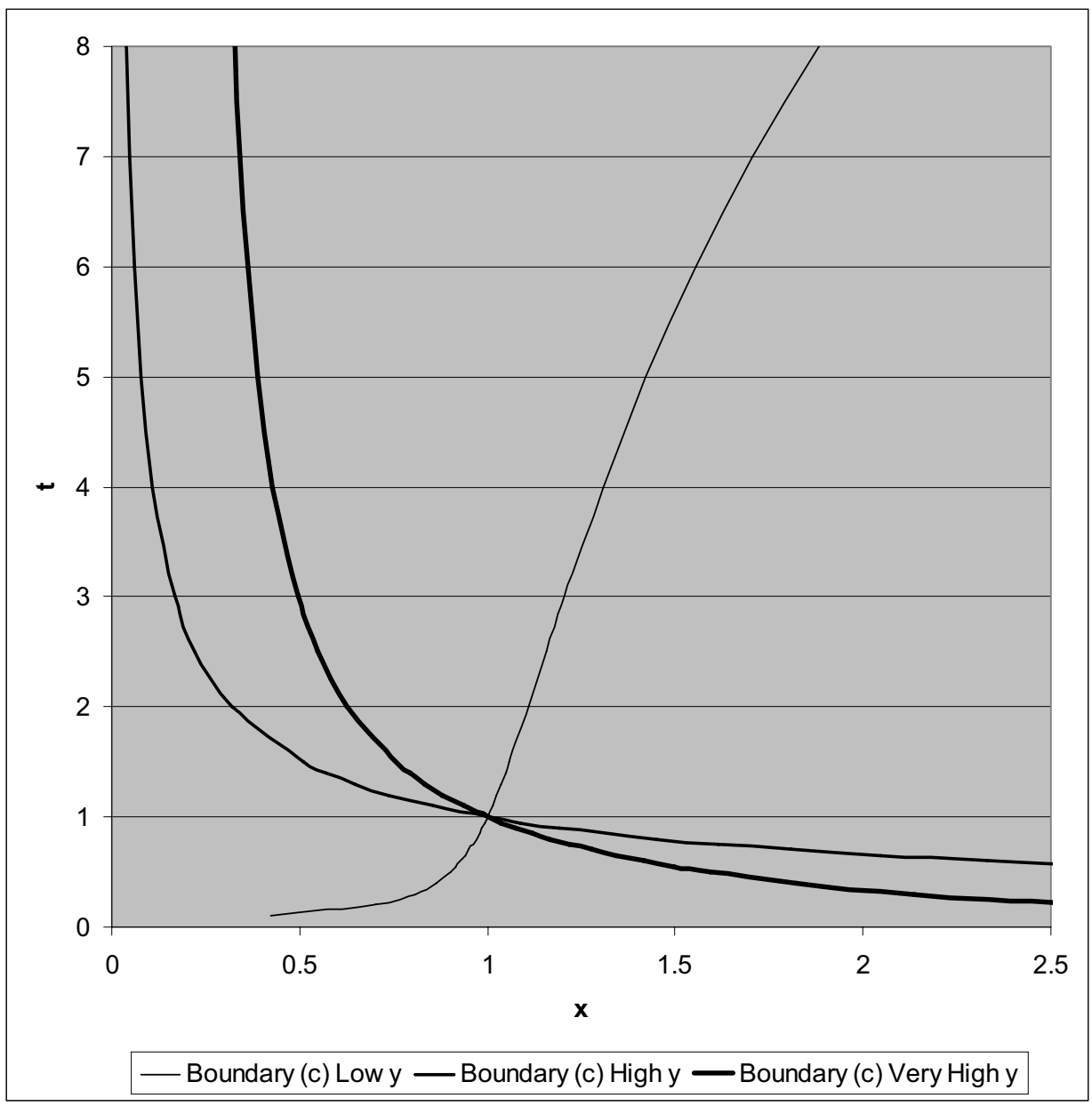


for the more able child. This observation brings out a feature of the model. It is not the abilities if the child that drive the results: it is the parents' preferences, for whatever reason.

(e)

$$
\text { Here } \epsilon_{1}=\frac{T_{1}}{T_{1}+T_{2}} \quad \epsilon_{2}=\frac{T_{2}}{T_{1}+T_{2}}, \text { with, as before, } \frac{T_{2}}{T_{1}} \equiv t>1,
$$

hence $T_{1}=\frac{2 T}{1+t}$ and $T_{2}=\frac{2 t T}{1+t}$. We also use the notation $y=z T=2 S$ in this case.

The first-order condition is $V_{1}-V_{2}=0$, with $V_{1} \equiv \frac{1+\beta t}{S_{1}}-\frac{1}{S_{1}+T_{1}}$ and $V_{2} \equiv \frac{t+\beta}{S_{2}}-\frac{t}{S_{2}+T_{2}}$

At $(S, S)$ let us suppose that $V_{1}(S, S) \geq V_{2}(S, S)$, which would imply $S_{1}^{*} \geq S_{2}^{*}$. This means:

$$
\begin{gathered}
\frac{1+\beta t}{S}-\frac{1}{S+T_{1}} \geq \frac{t+\beta}{S}-\frac{t}{S+T_{2}} \text { or } \quad(1-\beta) \leq \frac{S^{2}}{\left(S+T_{1}\right)\left(S+T_{2}\right)} \text { or } \\
(1-\beta) \leq \frac{z^{2}}{(z+4 /(1+t))(z+4 t /(1+t))}
\end{gathered}
$$

Developing and simplifying, $z^{2}(\beta /(1-\beta))-4 z-16 t /(1+t)^{2} \geq 0$ or

$$
y / T \equiv z \geq 2((1-\beta) / \beta)\left\{1+\sqrt{1+4(\beta /(1-\beta))\left(t /(1+t)^{2}\right)}\right\}
$$

or

$$
y \geq y^{c}\left\{1+\sqrt{1+4(\beta /(1-\beta))\left(t /(1+t)^{2}\right)}\right\}
$$

When $y$ is larger than the fraction of $y^{c}$ defined above, the least favoured child, who is also the easier one to motivate, is set a higher goal. That fraction of $y^{c}$ is larger, the larger $\beta$ is and the smaller $t$ is; that is the stronger emulation is and the less difference there is between the siblings. When $y$ is smaller, the ordering of goals is reversed. 
Putting it another way, when parents favour the more difficult child and emulation is weak, that child receives more coaching; this is more likely to happen when emulation is strong?

$$
\begin{gathered}
\text { Here } \epsilon_{1}=\frac{T_{2}}{T_{1}+T_{2}} \quad \epsilon_{2}=\frac{T_{1}}{T_{1}+T_{2}}, \quad \text { the rest is as in (e) } \\
\text { Now } V_{1} \equiv \frac{t+\beta}{S_{1}}-\frac{t}{S_{1}+T_{1}} \quad \text { and } \quad V_{2} \equiv \frac{1+\beta t}{S_{2}}-\frac{1}{S_{2}+T_{2}}
\end{gathered}
$$

We follow a procedure similar to case (e) to show that

$$
\begin{gathered}
S_{1}^{*} \geq S_{2}^{*} \quad \text { requires } z^{2}+4 z-16((1-\beta) / \beta)\left(t /(1+t)^{2}\right) \leq 0 \text { or } \\
y / T \equiv z \leq 2\left\{-1+\sqrt{1+4((1-\beta) / \beta)\left(t /(1+t)^{2}\right)}\right\}
\end{gathered}
$$

When $y$ is smaller than the fraction of $T$ defined above the most favoured child, who is also the easier one to motivate, is set a higher goal. That fraction of $T$ is larger, the smaller $\beta$ and $t$ are;that is the weaker emulation is and the less difference there is between the siblings. When $y$ is larger, the ordering of goals is reversed, which can also be stated as: When $y$ is larger than a fraction of $T$ the least favoured child, who is also the harder one to motivate, is set a higher goal. This makes it easier to compare with the result of case (e); the fraction of $T$ though, now decreases with $\beta$.

\section{Conclusion}

We have presented a model where the probability distribution over the space of an agent's achievements depends not only on her ability and effort, but also on the goals set for her (aka the intensity of her training program). The agent chooses her effort according to her utility net of perceived cost 
of effort. Chosen effort is a single-peaked function of the set goal and is inversely proportional to the perceived unit cost of effort. One of the parameters in her utility function is the difficulty the pricipal has to motivate her. Unsurprisingly the more difficult she is to motivate, the more training she requires.

The principal incurs costs in setting goals, i. e. coaching the agent, and subtracts these costs from the maximand. The agent's perceived unit cost of effort is inversely proportional to an 'emulation function' that depends on the training undertaken by rival agents. This is one of the essential mechanisms of the model.

In a situation where two principals separately attempt to motivate two rival agents we find a unique Nash equilibrium if each agent's ability exceeds the difficulty of training, both from the point of view of the agent's difficulty and the principal's. If not there may be no Nash equilibrium, or a stableunstable pair.

In the second half of the paper we turn our attention, not to teams, but ot families where parents have a more caring attitude than coaches. For the latter, theperformances of athletes are perfect substitutes; for parents the elasticity of substitution is 1 . A crucial parameter in our analysis is the 'critical value' of the educational budget of parents. It is large if emulation is weak and small if emulation is strong. The size of this critical value is inversely related to the strength of emulation.

We envisage several versions of parents' preferences.

- If parents care equally for both childrent hey will allocate a larger share of the budget to the more difficult child.

- If the children are twins but the parents nonetheless prefer one of them, they will devote more resources to the favourite if emulation is weak. However if emulation is strong the situation is reversed: parents devote more resources to the less favourite child so as to decrease the favourite's peceived 
cost, hence boost that child's effort. We also see that this reversal occurs at higher income - parents have done all they could for their preferred child; they now work through the twin.

For a fixed educational budget, an increasing difficulty to motivate the twins always turn to the advantage of the favourite.

- If parents base their their preferences on the respective abilities of the children, we find that it doesn't matter whether they prefer the more able or the less able. The resuts are the same once put in terms of "more liked" and "less liked". When emulation is weak a child who is both preferred and more difficult will attract more coaching. only if a child is only slightly preferred and much more difficult to motivate will parents set him or her a lower goal. They are then using the other child to stimulate the preferrd one; all other avenues having been exhausted.

When emulation is very strong ( this means a relatively high educational budget) the situation is reversed. The preferred child is more often set a lower goal, the parents concentrating on stimulating him or her through emulation from the other child. This is only reversed when the preferred child is much more difficult to motivate.

- When parents' preferences are dictated by the ease of motivating a child, weak emulation implies a stronger training program for the easier child. Strong emulation and strong differences in attitudes to work will reverse this.

Therefore we have shown that in many circumstances the emulation process reverses our naive intuition. There are now two distinct ways of prodding children or athletes to success: direct coaching and emulation through sibling rivalry. It is not a pretty world!

In a different situation where one principal coaches both agents and is keen on the sum of their performances (medal tally), we find that the principal tries harder and that (the sum of the) performances are better. 


\section{References}

[1] Beggs, W.D. (1990), Goal Setting in Sports, in J. Graham-Jones and L. Hardy (ed.), Stress and Performance in Sports, John Wiley and Sons, pp.155-191

[2] Bell, K. F. (1983), Championship Thinking: The Athlete's Guide to Winning Performance in All Sports, Englewood Cliffs, New Jersey, PrenticeHall.

[3] Bentham, Jeremy,(1811) Oeuvres de Jeremy Bentham, Vol 2, Theorie des Peines et Recompenses 131-139, Haumann, Brussels,

[4] Botterill, C. (1983), Goal Setting for Athletes with Examples from Hockey, in Martin, G.L., Hrycaiko, D. (eds.) Behavior Modification and Coaching: Principles, Procedures, and Research, Springfield, Il., Charles C. Thomas.

[5] Clark, Damon (2007), Selective Schools and Academic Achievement. IZA Discussion Paper, University of Florida.

[6] Dana, James D Jr (2005), Strategic differentiation and strategic Emulation in Games with Uncertainty, The Journal of Industrial Economics, Vol 53, no 3, 417-432.

[7] Brown, Clair (1994), The American Standards of Living, Cambrige, Mass.

[8] Cury, F. and P. Sarrazin, (1993), Motiver les Eleves et Reduire le Stress des Athletes. Analyse des Contributions de la Fixation des Buts a l'Amerioration de la Performance, in J.P. Famose (ed.), Cognition et Performance, Paris, INSEP Publications, 271-300. 
[9] Grush, Rick (2002) An introduction to the main principles of emulation: motor control, imagery, and perception, University of California at San Diego.

[10] Hillman, Arye L., and John Riley, 1989, "Politically Contestable Rents and Transfers", Economics and Politics 1: 17-39.

[11] Hardy, L., Maiden, D.S., and K. Sherry (1986), Goal setting and performance anxiety, Journal of Sports Sciences, Vol. 4, 233-4.

[12] Kaufman, B.E. (1999), Emotional Arousal as a Source of Bounded Rationality, Journal of Economic Behavior and Organization 38, 135-144

[13] Locke, E. A. and G.P. Latham (1990a), A Theory of Goal Setting and Task Performance, Englewood Cliffs, N.J., Prentice-Hall

[14] Locke, E. A. and G. P. Latham (1990b), Work Motivation and Satisfaction: Light at the End of the Tunnel, Psychological Science, Vol 1, 240-6.

[15] Mas, A. and E. Moretti, (2006), "Peers at Work", NBER Working paper 12508.

[16] Petri, H. (1986) Motivation: Theory and Research, 2nd edition, MIT Press, Cambridge, MA.

[17] Thompson, Doreen E and Russell, J. (2004) The ghost condition: Imitation versus Emulation in young childrens observational learning. Development Psychology, 40 (5). pp. 882-889.

[18] Tullock, G., 1980, Efficient Rent Seeking, in J. M. Buchanan, R. Tollinson and G. Tullock (eds.), Toward a Theory of Rent Seeking Society, Texas A\&M University Press, College Station. 
[19] Veblen, Thornstein, (1924) The Theory of the Leisure Class, Allen and Unwin, London

[20] Yerkes, R.M., and J. D. Dobson (1908), The relation od Strength of Stimulus to Rapidity of Habit Formation, Journal of Comparative Neurology and Psychology 18: 459-82. 